\title{
Adherence of primary care physicians in Aseer region, Saudi Arabia to the National Protocol for the Management of Asthma
}

\author{
A. Abudahish ${ }^{7}$ and H. Bella ${ }^{2}$
}

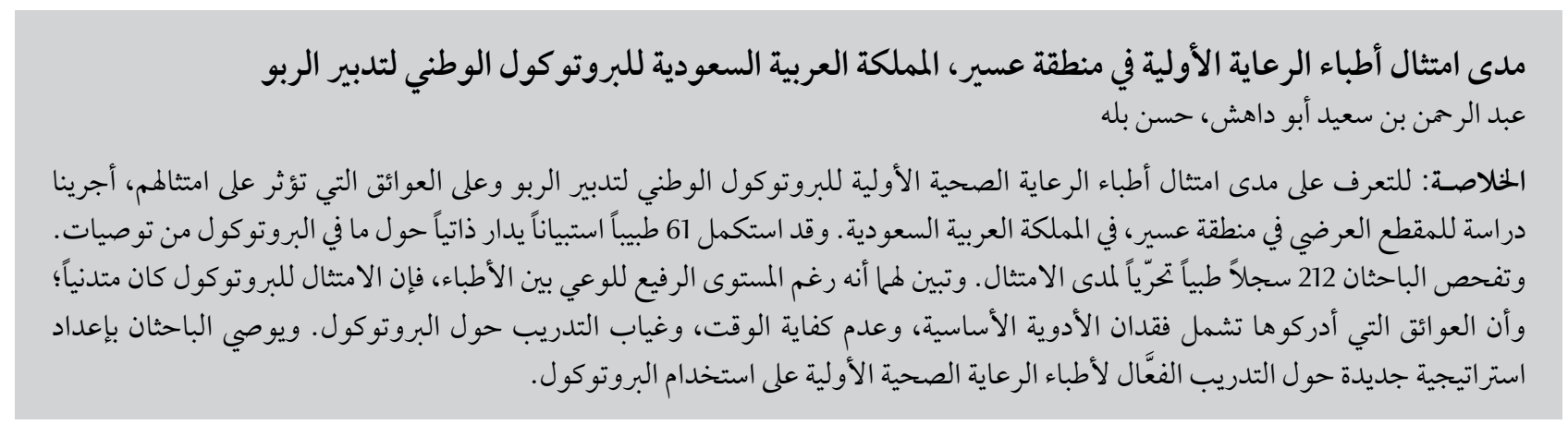

ABSTRACT To determine adherence of primary health care (PHC) physicians to the National Protocol for the Management of Asthma and barriers affecting adherence, we conducted a cross-sectional study in Aseer region, Saudi Arabia. Sixty-one PHC physicians completed self-administered questionnaires on the protocol recommendations. We also checked 212 medical records for adherence. Despite high awareness among the physicians, adherence to the protocol was low: perceived barriers included lack of essential medications, insufficient time and lack of training on the protocol. We recommend establishing a new strategy for effective training of $\mathrm{PHC}$ physicians on the protocol.

Adhésion des médecins de soins de santé primaires au National Protocol for the Management of Asthma [Protocole national de prise en charge de l'asthme] dans la région de l'Asir (Arabie saoudite)

RÉSUMÉ Afin d'évaluerl'adhésion des médecins de soins de santé primaires au National Protocol forManagement of Asthma [Programme national de prise en charge de l'asthme] et les éléments pouvant faire obstacle à cette adhésion, nous avons effectué une étude transversale dans la région de l'Asir, en Arabie Saoudite. Soixante et un médecins de soins de santé primaires ont rempli un auto-questionnaire sur les recommandations du protocole. Nous avons également vérifié l'adhésion au protocole dans 212 dossiers médicaux. Malgré la forte sensibilisation des médecins à ce sujet, cette adhésion était faible. Les obstacles identifiés sont notamment le manque de médicaments essentiels et de temps ainsi qu'une carence en formation sur le protocole. Nous recommandons la mise en place d'une nouvelle stratégie visant à former efficacement les médecins de soins de santé primaires au protocole. 


\section{Introduction}

Bronchial asthma is a common, serious health problem throughout the world. Guidelines were established in many countries to control this problem. The World Health Organization (WHO) and the National Heart, Lung, and Blood Institute (NHLBI) in the United States of America (USA) established guidelines to reduce the incidence of morbidity and mortality of asthma. In 1995, the National Protocol for the Management of Asthma in Saudi Arabia was published using a stepwise approach [1]. In 2000, the 3rd edition of the protocol was published with changes in the classification of the severity of asthma and emphasis on anti-inflammatory medications as well as improvements in the health education section [2].

Despite the fact that NHLBI guidelines for asthma management were established more than a decade ago in the USA, a review article based on previous studies conducted in that country has suggested the presence of a gap between actual asthma care and the recommendation of the NHLBI guidelines [3]. Abudahish and Bella found that primary health care (PHC) physicians' knowledge of asthma care in Aseer Region, Saudi Arabia, was poor (mean total score 37\%) [4].

The protocol published by the Ministry of Health in Saudi Arabia is now in its 3rd edition, and more than 2000 PHC physicians have been trained on how to apply it in their practice. Our objective was, therefore, to evaluate the adherence of PHC physicians to the recommendations of the National Protocol for Management of Asthma in this region of Saudi Arabia.

\section{Methods}

This cross-sectional study was carried out during June-July 2001; it covered urban and rural PHC centres located in Abha and Khamis Mushayt towns in southern Saudi Arabia. Two methods were used: self-reporting of $\mathrm{PHC}$ physicians and review of medical records.

Determination of sample size and selection of participants has been described previously [4].

A 2-stage, stratified, random sample with proportional allocation was used to select medical records based on the average number of patients seen daily. In the first stage the PHC centres were divided into 2 strata (urban and rural). In the second stage, a sample of medical records was selected proportionally from each stratum. The total number of randomly selected PHC centres was 11 (5 urban and 6 rural), and 212 medical records were selected (130 from urban centres and 82 from rural centres).

Certain inclusion and exclusion criteria were adopted to validate the results of the study:

- All PHC physicians had worked in PHC centres in Saudi Arabia for at least 1 year. Physicians who had worked for less than 1 year were excluded. Physicians who work in Saudi Arabia for at least 1 year are probably aware of the national protocol of asthma management. They have probably attended workshops on asthma management and practice on the protocol.

- All PHC centres were directly under the supervision of the Directorate of Health Affairs in Aseer Region.

All asthma records in the randomly selected PHC centres and documented clinic visits for asthma patients who had been attending the clinic for at least 1 year at the time of survey were included. If patients were first seen in the clinic after this, their medical records were excluded.

The response rate of the $\mathrm{PHC}$ physicians was $100 \%$. The reason for this was a directive they had from the Director of Health Affairs in Aseer Region to comply. The investigators also made compliance attractive by announcing benefits to the participants that included updating them on bronchial asthma.

A checklist was designed to assess the status of recording of data in medical records of asthma patients. It covered demographic data, diagnosis and severity, monitoring, medications, follow-up, health education, referral and the management plan. Two types of medical records were found in the $\mathrm{PHC}$ centres: a traditional medical record designed for all patients regardless of their conditions and a special medical record specifically designed for asthma patients characterized by a cover page, flow chart, management and health education items on asthma.

SPSS was used for statistical analysis. Both descriptive and inferential data analysis was performed. Significance level was set at $P<0.05$. Chi-squared and $t$-test were used as appropriate.

\section{Results}

Most of the PHC physicians (82.0\%) we studied had heard of the National Protocol for Management of Asthma and nearly three-quarters had read it (Table 1). Less than half of those who had read the protocol had been trained on it and over $90 \%$ were not using the most recent edition.

More than a quarter of physicians who had read the protocol had read it only once. Half said they reviewed it every 3-6 months.

Almost all the physicians who read the protocol (97.8\%) agreed generally with the text/contents, but $62.2 \%$ thought that the classification of the severity of asthma was difficult.

About half the respondents reported having the skills for proper use of the peak flow meter (PFM) and 63.9\% reported having the ability to interpret the readings. Over 80\% thought that adherence to the protocol would improve outcomes in the management of asthma; however, two-thirds said 


\begin{tabular}{|c|c|c|}
\hline \multicolumn{3}{|c|}{$\begin{array}{l}\text { Table } 1 \text { Factors influencing adherence of physicians }(n=61) \text { to the National } \\
\text { Protocol for Management of Asthma }\end{array}$} \\
\hline Factor & No. & $\%$ \\
\hline \multicolumn{3}{|l|}{ Physicians who: } \\
\hline Had heard of the protocol & 50 & 82.0 \\
\hline Had read the protocol & 45 & 73.8 \\
\hline Had been trained on the protocol & $21^{\mathrm{a}}$ & 46.7 \\
\hline Agreed/strongly agreed with the protocol & $44^{a}$ & 97.8 \\
\hline Thought that classification of asthma severity was difficult & $28^{\mathrm{a}}$ & 62.2 \\
\hline Could demonstrate proper use of PFM & 30 & 49.2 \\
\hline Had the ability to interpret readings of PFM & 39 & 63.9 \\
\hline Thought that adherence to protocol improved outcome & 51 & 83.6 \\
\hline Had insufficient supplies of essential needs & 38 & 62.3 \\
\hline Had enough time to manage cases properly & 30 & 49.2 \\
\hline Said their patients were not satisfied with care & 18 & 29.5 \\
\hline $\begin{array}{l}\text { Said their patients had misconceptions about asthma } \\
\text { medications }\end{array}$ & 34 & 55.7 \\
\hline Said no language barriers influenced adherence & 48 & 78.7 \\
\hline \multicolumn{3}{|l|}{ Current edition used by physicians ${ }^{\mathrm{a}}$} \\
\hline $1^{\text {st }}$ & 22 & 48.9 \\
\hline $2^{\text {nd }}$ & 20 & 44.4 \\
\hline $3^{\text {rd }}$ & 2 & 4.4 \\
\hline \multicolumn{3}{|l|}{ Frequency of reviewing the protocol ${ }^{\mathrm{a}}$} \\
\hline Weekly & 5 & 11.1 \\
\hline Every 3 months & 13 & 28.9 \\
\hline Every 6 months & 9 & 20.0 \\
\hline Yearly & 5 & 11.1 \\
\hline Once & 13 & 28.9 \\
\hline
\end{tabular}

${ }^{a}$ Of the 45 physicians who read the protocol. PFM = peakflow meter.

they did not have sufficient supplies of essential needs, e.g. PFMs and antiinflammatory medication, to manage asthma cases.

Nearly one-third of the participants stated that their asthma patients were not satisfied with the care delivered at their PHC centres while 55.7\% thought the patients' misconceptions related to side-effects of medications could affect adherence to the protocol. About onefifth of PHC physicians were suffering from a language barrier.

When asked about possible barriers influencing their adherence to the protocol, only 37 of the 61 physicians responded (Table 2). Just over 40\% cited "lack of essential medications", 32.4\% cited "non-compliant patients", $27.0 \%$ management of asthma. Diagnosis of asthma was recorded in $93.9 \%$ of the special asthma records and in $78.5 \%$ of the traditional records, with the difference statistically significant $(P=0.001)$. Health education (53.7\%) and followup $(26.5 \%)$ were reported in the special asthma records, but not reported at all in the traditional records. There was no significant difference in recording medications and the availability of feedback sheets.

The National Protocol for Management of Asthma was available in more than half of the selected PHC centres (54.5\%). Asthma registers, weighing scale, height measure and oxygen cylinders were available in all $11 \mathrm{PHC}$ centres. Nearly two-thirds of the centres were supplied with educational material in the form of pamphlets and boosters and 5 centres were supplied with PFMs, but in 3 of these the meters were not working. Most of the centres (90.9\%) were supplied with $\beta 2$ agonists but no steroid inhalers or sodium cromoglycate were available in any.

\section{Discussion}

Despite thehighawarenessamong PHC physicians of the National Protocol for Management of Asthma, we found that adherence to the protocol was poor, similar to a study in Chicago which showed poor compliance to the NHLI guidelines [5]. In a study in selected outpatient clinics caring for asthma patients in 9 developing countries, practitioners tended to underutilize the peak expiratory flow rate in assessing their patients and underutilized inhaled corticosteroids in treatment [6]. In a previous study on knowledge of the National Protocol for Asthma Management, the mean total score for PHC physicians in Aseer Region was 37.7\% [4].

An understanding of the barriers that affect adherence to the protocol is necessary to encourage change in the 


\begin{tabular}{lcc}
\hline $\begin{array}{l}\text { Table } 2 \text { Physicians' perceptions of barriers affecting adherence to the asthma } \\
\text { protocol }\end{array}$ & No. ${ }^{\text {a }}$ & $\%$ \\
\hline Barrier & 15 & 40.5 \\
Lack of essential medications & 12 & 32.4 \\
Non-compliant patients & 10 & 27.0 \\
Insufficient time & 8 & 21.6 \\
Lack of training & 7 & 18.9 \\
Lack of instruments & 5 & 13.5 \\
Shortage of manpower & 4 & 10.8 \\
Unavailable protocol & 4 & 10.8 \\
Lack of health education & 3 & 8.1 \\
No appropriate coordination with hospital & 1 & 2.7 \\
Patient wants referral & 1 & 2.7 \\
No asthma record & 1 & 2.7 \\
Lack of nurses trained in asthma care & 1 & 2.7 \\
Improper follow-up system & & \\
\hline
\end{tabular}

${ }^{a}$ Total 37 physicians who responded to the open question out of 61 primary health care physicians.

practice of the treating doctors. The National Protocol was effective in improving some areas of management and the status of recording essential data, including patient education.

Cabana et al. designed a framework which is useful to analyse the barriers influencing the adherence to guidelines
[7]. There were 7 general categories of barriers; barriers affecting physician's knowledge, attitudes, or behaviour. These barriers should be considered when guidelines implementers have established their guidelines. Additionally, some physicians were not of Arab origin and did not speak Arabic, and some of the Arabic speakers did not know how to communicate with the patients in the local dialect. If any barrier exists, compliance to the guidelines would be poor. Cabana's framework, which was designed to find barriers affecting adherence for any guidelines (not specifically asthma guidelines), was used in our study as appropriate: we tried to identify barriers relevant to asthma care

Awareness on the national protocol among PHC physicians in Abha and Khamis Mushayt sectors was high. Most PHC physicians in the current study had heard of the National Protocol, and nearly three-quarters of physicians had read it. Regarding the familiarity of physicians to the protocol, few PHC physicians had read the third and last edition. Half the PHC physicians who had read the protocol still used the first edition, suggesting that the distribution efforts of the Ministry of Health were limited, and mandates an action to develop a new strategy to make sure that all the new editions of the protocol are available to all $\mathrm{PHC}$ centres. This might mean that the

\begin{tabular}{|c|c|c|c|c|c|c|c|}
\hline \multirow[t]{3}{*}{ Information recorded } & \multicolumn{6}{|c|}{ Type of asthma record } & \multirow[t]{3}{*}{$P$-value ${ }^{\mathrm{a}}$} \\
\hline & \multicolumn{2}{|c|}{ Special $(n=147)$} & \multicolumn{2}{|c|}{ Traditional $(n=65)$} & \multicolumn{2}{|c|}{ Total $(n=212)$} & \\
\hline & No. & $\%$ & No. & $\%$ & No. & $\%$ & \\
\hline \multicolumn{8}{|l|}{ Riskfactor } \\
\hline Occupation & 99 & 67.3 & 0 & 0.0 & 99 & 46.7 & $<0.001$ \\
\hline History of smoking & 84 & 57.1 & 0 & 0.0 & 84 & 39.6 & $<0.001$ \\
\hline Education & 76 & 51.7 & 0 & 0.0 & 76 & 35.8 & $<0.001$ \\
\hline History of atopy & 52 & 35.4 & 0 & 0.0 & 52 & 24.5 & $<0.001$ \\
\hline Family history of asthma & 54 & 36.7 & 3 & 4.6 & 57 & 26.9 & $<0.001$ \\
\hline Trigger factors & 54 & 36.7 & 1 & 1.5 & 55 & 25.9 & $<0.001$ \\
\hline \multicolumn{8}{|l|}{ Management data } \\
\hline Diagnosis & 138 & 93.9 & 51 & 78.5 & 189 & 89.2 & 0.001 \\
\hline Medication & 104 & 70.7 & 41 & 63.1 & 145 & 68.4 & NS \\
\hline Health education & 79 & 53.7 & 0 & - & 79 & 37.3 & $<0.001$ \\
\hline Follow-up & 39 & 26.5 & 0 & - & 39 & 18.4 & $<0.001$ \\
\hline Management plan & 20 & 13.6 & 0 & - & 20 & 9.4 & $<0.001$ \\
\hline Monitoring & 18 & 12.2 & 0 & - & 18 & 8.5 & 0.001 \\
\hline Feedback sheets available & 5 & 3.4 & 5 & 7.7 & 10 & 4.7 & NS \\
\hline
\end{tabular}

${ }^{a}$ Chi-squared.

$N S=$ not statistically significant $(P \geq 0.05)$. 
protocol was unfamiliar to physicians, especially since nearly one-third of the physicians we studied who had read the protocol had read it only once.

Limitations of this study included the relatively short time since the protocol was introduced and the study type which, although appropriate, was dictated by the time and resources available for the study.

As noted earlier, difficulty in classification of asthma severity constitutes a barrier to adherence to the protocol. Therefore, severity classification should be simplified to suit the understanding of PHC physicians. Disagreement amongst physicians regarding classification of severity was a barrier to adherence, as shown in the Cabana et al. study [6]. The National Protocol seems to be impractical for clinical practice because of the complicated grading of severity. We suggest that the National Protocol be simplified so that all $\mathrm{PHC}$ physicians are able to use it.
The physicians in our study had positive attitudes towards the outcome of adherence to the protocol. However, the inadequate basic training of physicians and their experiences, which were not based on scientific approaches, might contribute as barriers to adherence.

The focus should then be concentrated on regular training programmes for all physicians, with documentation of performance skills. Continuing education of $\mathrm{PHC}$ physicians on the protocol based on current management guidelines and adoption of easy-to-use forms may facilitate improved care of patients with asthma in the PHC centres.

Special asthma records might help physicians or nurses in recording data important for monitoring and prognosis of asthma. Although the existence of such records significantly improved data recording, it is still not satisfactory. Busy clinics and lack of manpower contribute as obstacles in recording essential data for management of asthma at PHC centres.

We suggest encouraging larger studies to asses the systems in place to enable adherence to protocol. By taking the system into account, interventions may be potentially much more effective in improving the quality of asthma care.

\section{Acknowledgements}

We would like to thank all PHC physicians who participated in the study. Special thanks to Dr Abdulla Al-Sharif, Director General of Aseer HealthAffairs, for his valuable support. Our thanks are also extended to the Chicago Asthma Surveillance Initiative (CASI) for supplying us with their original questionnaire. Thanks are also due to Dr Ahmad Bahnassy for his help in statistical analysis and to Dr Abdul-Aziz Al-Sabiani for reviewing the manuscript.

\section{References}

1. The National Scientific Committee of Bronchial Asthma. National protocol for management of asthma, 1st ed. Riyadh, Saudi Arabia, General Directorate of Health Centers, Ministry of Health, 1995.

2. The National Scientific Committee of Bronchial Asthma. National protocol for management of asthma, 3rd ed. Riyadh, Saudi Arabia, General Directorate of Health Centers, Ministry of Health, 2000.

3. Crim C. Clinical practice guidelines vs actual clinical practice: the asthma paradigm. Chest, 2000, 118(2 Suppl.):62-4S.

4. Abudahish A, Bella H. Primary care physicians' perceptions and practices on asthma care in Aseer region, Saudi Arabia. Saudi medical journal, 2006, 27(3):333-7.
5. Grant EN et al. Asthma care practices, perceptions, and beliefs of Chicago-area primary-care physicians. Chest, 1999, 116:145-54S.

6. Aït-Khaled $\mathrm{N}$ et al Implementation of asthma guidelines in health centres of several developing countries. International journal of tuerculosis and lung disease, 2006, 10(1):104-9.

7. Cabana MD et al. Why don't physicians follow clinical practice guidelines? Journal of the American Medical Association, 1999, 282:1458-65. 